\title{
Redefining clinical leadership for team-course development
}

\author{
Øystein Evjen Olsen ${ }^{* 1,2}$, Sissel Eikeland Huseb $\varnothing^{3}$, Sigrun Anna Qvindesland ${ }^{4}$, Helge Lorentzen ${ }^{4}$ \\ ${ }^{1}$ Stavanger University Hospital, Stavanger, Norway \\ ${ }^{2}$ Center for International Health, University of Bergen, Bergen, Norway \\ ${ }^{3}$ University of Stavanger, Stavanger, Norway \\ ${ }^{4}$ Stavanger Acute Medicine Foundation for Education and Research (SAFER), Stavanger, Norway
}

Received: May 29, 2015

DOI: $10.5430 /$ jha.v4n5p52
Accepted: July 5, $2015 \quad$ Online Published: July 9, 2015

URL: http://dx.doi.org/10.5430/jha.v4n5p52

\begin{abstract}
Objective: Value choices are rooted in the philosophical deliberations of Aristotle, Levinas and Gadamer. Balancing the needs of "the other" with societal and institutional needs to meet the objectives of "the cause" is core to the modern health systems priority setting debate. These value conflicts present themselves bed-side in the day-to-day decision-making processes. A clinical leadership (CL) framework should present solutions to this challenge.

Methods: The definition of CL is redefined to include four key values involved in this value conflict. These are 1) trust, 2) quality, 3 ) responsiveness and 4) efficiency. A CL in Teams course curriculum and design was developed to link these values to tools and to context in the hospital.

Results: A new definition of CL has provided a common formative framework useful in clinical settings for priority setting, evaluation and professional development. By the end of 2015 a total of 82 participants will have completed the course. It has been evaluated to be timely, feasible, flexible, relevant and sustainable.

Conclusions: Values influence how clinical leaders operate and have an important impact on their leadership abilities and how they respond to challenges. For clinical leaders and teams to work effectively it is crucial to develop common basic values. Developing a set of tools and reflective practice to understand the inter-relationship between values and how they can conflict or reinforce each other, contributes to improved quality of service, patient-centred care and workforce satisfaction.
\end{abstract}

Key Words: Clinical leadership, Values, Emergency department, Patient safety, Trust, Quality, Responsiveness, Efficiency

\section{INTRODUCTION}

Leadership is part of the human existence, taking responsibility for caring in the face of suffering and vulnerability of others. This argument is rooted in the thoughts of Emanuel Levinas and Aristotle and translated to the health service domain. ${ }^{[1,2]}$ Levinas describes a response to the individual suffering of "the other". In this ethics of proximity rational considerations are not considered part of the moral delibera- tion process leading to actions. Modern health policy debates however, exemplified in the current debate concerning the underlying management ideology of health services in Norway, struggle to incorporate the individual patient concern with the societal and institutional needs to prioritize resources between individuals and programs. ${ }^{[3]}$ Hans Georg Gadamer could be argued to take a systems perspective in which "the other" must be considered in a larger context of "the cause"

\footnotetext{
*Correspondence: Øystein Evjen Olsen; Email: oysteineo@gmail.com; Address: Stavanger University Hospital, Stavanger, Center for International Health, University of Bergen, Bergen, Norway.
} 
providing a wider legitimacy for the range of values included in the deliberation of moral actions. ${ }^{[4]}$ These perspectives are fundamental ethical descriptions of value interactions balancing between individual patient care and systems needs within a context of limited resource availability in the day to day priority setting processes handled by clinical personnel. At an institutional level clinical personnel need tools and mechanisms to reflect on the interplay between core health systems values and how they are impacted by day to day bedside decisions.

The aim of this article is to describe the rationale behind a new definition of clinical leadership (CL). An additional aim is to describe the transformation of this definition from theory to practice in a clinical setting through the development of a course curriculum.

\subsection{The rationale}

The rationale for developing a CL in Teams (CLT) course is primarily an acknowledgement of the absence of experienced doctors and nurses functioning as role models for younger and less experienced doctors and nurses. ${ }^{[5,6]}$ While senior doctors may be consulted to address clinical decisions, there is a trend towards reduced physical presence to reflect on

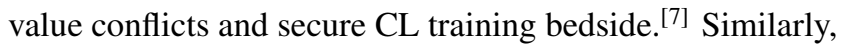
the role of the nurse-in-charge has been reformulated from a more historical apprenticeship model to "chief supervisor only" of the current quality management system at any given time. Healthcare education models also do not focus on the importance of CL. ${ }^{[6,8]}$

At the Stavanger University Hospital (SUH), the regional office of the Norwegian Board of Health Supervision (NBHS) conducted a follow-up evaluation from the 2008 report $^{[9]}$ of the services at the ED of the hospital in the spring of 2013. ${ }^{[10]}$ One of the conclusions of this report pointed to the inadequate presence of medical personnel (doctors) with adequate CL skills. The hospital responded to these conclusions by establishing several working groups with a Steering Committee involving the top leadership of the hospital. It was concluded that there was a need to institutionalize a process to secure CL skills among key health personnel.

In addition, several other health policy developments within the Norwegian health care system have emerged to reinforce attention to CL in an Emergency Department (ED) and clinical wards context. Firstly, there is currently a process within the Ministry of Health and Social Welfare aimed at introducing a separate specialty in Emergency Medicine. ${ }^{[11]}$ Secondly, there is a development of separate municipal medical care facilities with the aim of closing the service gap between specialist hospital services and municipal health

Published by Sciedu Press services. ${ }^{[12]}$ CL skills within the ED and clinical wards of hospitals are important to contribute to effective management and flow of patients towards these services. Thirdly, there have been developed new guidelines for the service levels, availability and distribution of emergency services countrywide. ${ }^{[13]}$ CL skills at specialist care levels are vital to the effective collaborative clinical processes overlapping, and at times extending into, pre-hospital services levels. Finally, the already mentioned conclusions of the NBHS of 2008 and 2013 give hospitals in general, and SUH in particular, no other options but to improve CL skills among staff in the ED to comply with the recommendations presented.

It was decided that the definition of CL needed to be reformulated to meet these developments. The process aimed at presenting a new definition of CL rooted in a value-centred practical context to facilitate improved bedside decision making and ward management needs. This involved the development of a set of tools for clinical personnel in the daily ethical challenge of balancing health systems values and taking responsibility for patient care. This was conducted through the development of a CLT course.

\subsection{The setting}

The CLT course was started in 2013 at SUH, Norway and developed in collaboration with Stavanger Acute Foundation for Education and Research (SAFER) and the University of Stavanger (UiS). The hospital is located in an urban setting and triages approximately 30,000 patients per year. There is approximately 7,200 staff in 120 different professional categories. SUH serves 18 municipalities with a population of about 350,000 in the south-west of Norway. The hospital is an academic teaching facility for nursing students from UiS and medical students from the University of Bergen.

\section{Methods}

\subsection{CL - reformulating the concept}

The term "CL" first occurred in a text written by Rocchiccioli and Tilbury ${ }^{[14]}$ who argued that excellence in clinical practice is fostered in an environment where staff are empowered and where there is a vision for the future. Lacking a standard definition, CL is generally poorly understood. ${ }^{[15]}$ Nevertheless it is a much used term. The National Health Service in Scotland ${ }^{[16]}$ refers to CL within a clinical domain and describes CL in terms of driving service improvement and effective management of teams to provide excellence in patient care. ${ }^{[17]}$ Effective CL also requires leadership skills for team building, confidence in and respect for others and a combination of expertise and communication skills. ${ }^{[17,18]}$ Additionally, CL is about facilitating evidence-based practice and improved patient outcomes at the front line. ${ }^{[19]}$ 
$\mathrm{CL}$ in teams is a prerequisite for quality of care and patient safety. ${ }^{[20,21]}$ The provision of services involves a wide range of actors and professions. CL skills in teams are not well developed among healthcare workers. ${ }^{[22]}$ The complexity of patient care and crowding in the ED and hospital wards are associated with a number of negative health outcomes, including unnecessary deaths, increased waiting times and a decrease in quality of care. ${ }^{[23]}$ These factors necessitate the development of strong interdisciplinary team skills among medical personnel. ${ }^{[24,25]}$ In Norway, inadequate management and leadership affect the day-to-day running of patient services. ${ }^{[26]}$ There are also correlations between $\mathrm{CL}$ and staff morale, the quality of patient care and trust. ${ }^{[27-29]}$ Leadership and team training can optimize multidisciplinary teamwork and improve patient safety as such programs have the potential to develop individual skills, influence workplace culture and teach human factor techniques. ${ }^{[30-32]} \mathrm{CL}$ in teams is considered critical to ensure safe care and improvement of patient outcomes and efficiency indicators. ${ }^{[33,34]}$ Research demonstrates that $\mathrm{CL}$ in teams is vital towards achieving effective team performance and reducing patient harm due to medical error. ${ }^{[34-37]}$

$\mathrm{CL}$ is not the preserve of any one professional or disciplinary group, nor is it the exclusive domain of those in formal leadership or management positions. ${ }^{[19,34-38]}$ The term CL in the context of this study neither includes development of managerial medical leadership skills described elsewhere, ${ }^{\text {[39] }}$ nor $\mathrm{CL}$ in relation to change and improvement of health service. ${ }^{[40]}$

The aim of reformulating the concept of CL is to generally address the health policy development needs of the Norwegian health services, and specifically describe the values previously transferred from senior to junior health personnel through mentoring and role model relationships in the clinical setting. Having defined these values, the hospital could proceed to develop and implement a structured course curriculum and a set of tools to handle conflicts and synergies between these values in daily clinical practice.

\subsection{Defining CL - four core values}

Based on the previously described attributes and outcomes of $\mathrm{CL}$, as well as through a normative, deliberative process in the working groups, including a review of descriptions of the overarching goals and ideals of health care systems, ${ }^{[41,42]}$ four core values were defined to constitute the content of the apprentice to mentor relationship of the past. These values were 1) trust, 2) quality, 3) responsiveness and 4) efficiency. These four values provided the formative platform from which the course and tools were developed. Realising these values can have wide and multiple definitions they were derived and defined as follows:

(1) Trust. In this context, trust refers to the understanding of the concept as described by Giddens. ${ }^{[43]}$ Giddens states that trust rests on a vague and partial understanding, where some decisions are based on inductive inferences from past experiences believed in some way to be reliable for the present. In order for someone to trust their decision, good reason must combine with a further element that satisfies their "partial understanding". Giddens argues that trust acts as a medium of interaction between modern society's systems and the representatives of those systems. The grounds for this interaction are referred to as access points; the meeting ground for what he terms "facework" and "faceless" commitments. Facework commitment is dependent on the demeanour of the "expert" (in health systems, health professionals). Their level of professionalism, mannerisms, and other aspects of their personality affect our impressions and expectations. Faceless commitment is the perceived legitimacy, technical competence, and the ability of the "expert system" (e.g. the medical system). The notion of trust within the framework of the CL definition presented here focuses on trust within and between the healthcare system and providers, as a prerequisite for successful team performance. ${ }^{[35,42,44]}$ Trust between provider and patient is considered to be a function and result of the overall implementation of all the four values within the proposed CL definition.

(2) Quality. For the purpose of this CL framework quality is defined as the "degree to which health services for individuals and populations increase the likelihood of desired health outcomes and are consistent with current professional knowledge". ${ }^{[45]}$ Donabedian ${ }^{[46]}$ states that if structure, process and outcome are described, the most important aspects of quality are captured. There are two elements when considering performance of practitioners: one technical and the other interpersonal. Technical performance depends on the knowledge and judgment used in arriving at the appropriate strategies of care and on skill in implementing those strategies. Interpersonal relationship is the element where the patient communicates information with healthcare workers and healthcare workers among themselves. Through this exchange, the healthcare personnel provide information about treatment and care. ${ }^{[46]}$ Quality of care from the patient's perspective involves medical-technical competence of the caregivers, physical-technical conditions of the care organization, degree of identity-orientation in the atti- 
tudes and actions of the caregivers and socio-cultural atmosphere of the care organization. ${ }^{[47]}$ The process of providing quality of care in healthcare is inherently interdisciplinary, requiring physicians, nurses and allied health professionals from different specialties to work in teams. ${ }^{[29]}$ The proposed CL framework specifically emphasizes that definitions of what is good and bad quality will vary, but that the need to be continuously quality conscious and developing a quality focused culture $^{[48]}$ is imperative. Deming's ${ }^{[49]}$ "quality circle" for improvement of processes involving four stages: plan, do, check, and act, provides a model for reflection and skill development.

(3) Responsiveness. Responsiveness in the context of a system can be defined as the outcome that can be achieved when institutions and institutional relationships are designed in such a way that they are cognisant and respond appropriately to the universally legitimate expectations of individuals and society. ${ }^{[50]}$ Responsiveness can therefore be viewed from two angles. Firstly, the user of the health care system is often portrayed as a consumer with varying degrees of financing roles. Through taxes, insurance schemes or out-of-pocket spending, patients generate expectations to the service, often with an element of market mechanisms at play. Secondly, their right to adequate services are also institutionally secured through societal mechanisms. Responsiveness is related to safeguarding the legal rights of patients to adequate and timely care as specified in local, national and even global laws and regulations. This dimension is important in encounters between the patient and healthcare in which there is inherent market failure, primarily due to asymmetry of information, and the patient does not understand or does not have prerequisites for understanding their role as "consumer". $[50,51]$

(4) Efficiency. Efficiency and effectiveness are terms used interchangeably. ${ }^{[52]}$ For hospitals it is important to provide the best possible treatment and care given the available resources. ${ }^{[53]}$ The Agency for Healthcare Research and Quality ${ }^{[54]}$ defines efficiency as an attribute of performance that is measured by examining the relationship between a specific product (also called an output) and the resources used to create that product (also called inputs). Effectiveness can be understood as "mobilizing resources to accomplish tasks". [54] Effectiveness answers the question "are our objectives met with our available resources?" implying that more can be done with them, while efficiency answers the question "can waste be avoided given the same out- put?" implying that the same can be done with fewer resources. ${ }^{[55]}$

Having identified these four values as key to the execution of CL, the definition of CL has been formulated as follows:

"to take responsibility for clinical decision-making, within the scope of your role in a clinical team at any given time, with a patient-centred perspective addressing four key values: 1) trust, 2) quality, 3) responsiveness and 4) efficiency."

A key message is the importance of reflecting on the interrelationship between these values. In terms of priority-setting between patients and actions, values will inherently be in conflict with each other. ${ }^{[56]}$ Efficiency may have a negative impact on other values, such as quality and trust, if the wrong composition of input is chosen, e.g. staffing norm. Similarly, poor quality and lack of trust may have a negative impact on effectiveness. ${ }^{[52]}$ Poor performance on trust, quality and responsiveness is costly, inefficient and has scope for improved effectiveness. There is therefore not only an inherent conflict between the values in terms of priority setting but also a potential synergy between them in terms of improving the outputs and reaching the organizational goals. ${ }^{[57,58]}$ Improved trust may have a dramatic effect on efficiency, quality and responsiveness. Values reinforcing each other will contribute to improved working relations and improved staff morale. When values conflict, e.g. in the choice of attention by a nurse between two seriously ill patients, it will often lead to frustration to clinical personnel aiming to maximize each of these values at all times. This conflict has been described well by Hollnagel in the Efficiency-Thoroughness-Trade-Off (ETTO) principle. ${ }^{[59]}$

\subsection{Course design}

The CLT course emphasizes the need to consciously and continuously reflect on how each of these values are affected, compromised and prioritized in different clinical settings. While doctors and nurses are trained to be, and often consider themselves as "tailors", wanting to always take a holistic approach to each patient, they more often find themselves in a "manufacturing" situation, in which their role is limited and in which they might never see the end result. The course focuses on identifying the optimal role and approach within each different situation as they are responsible for patients with varying needs and colleagues with varying competences and responsibilities.

The overarching aim of the CLT course is to reinforce core health systems values and to foster an understanding of excellent day-to-day CL in teams and executing CL within a framework of existing resources and organisational structure. The specific goals of the CLT is for participants to 1) function 
as skilled operative leaders and clinical supervisors within their clinical every-day setting, 2) understand and improve patient safety and quality, 3) understand dynamics of patient flow and critically and efficiently use available resources and 4) improve trust between health personnel.

\subsubsection{Linking values to tools}

The process focused on developing a curriculum specifically introducing practical tools enabling a systematic analysis and critical reflection on the impact of actions and communication patterns on the four values. The curriculum places a heavy emphasis on these tools being evidence based and relies on the academic domains of systems engineering approaches, human factors and organizational aspects of safety. ${ }^{[48,60-62]}$

To facilitate the conceptual link between the four values and the practical tools, four main contextualized topics were established: basics, behaviour, team and safety. From these tools subtopics were then derived. The four core values were then integrated into each subtopic and tools implementation (see Table 1).

Table 1. Overview of course design: operationalizing the course linking CL values to tools

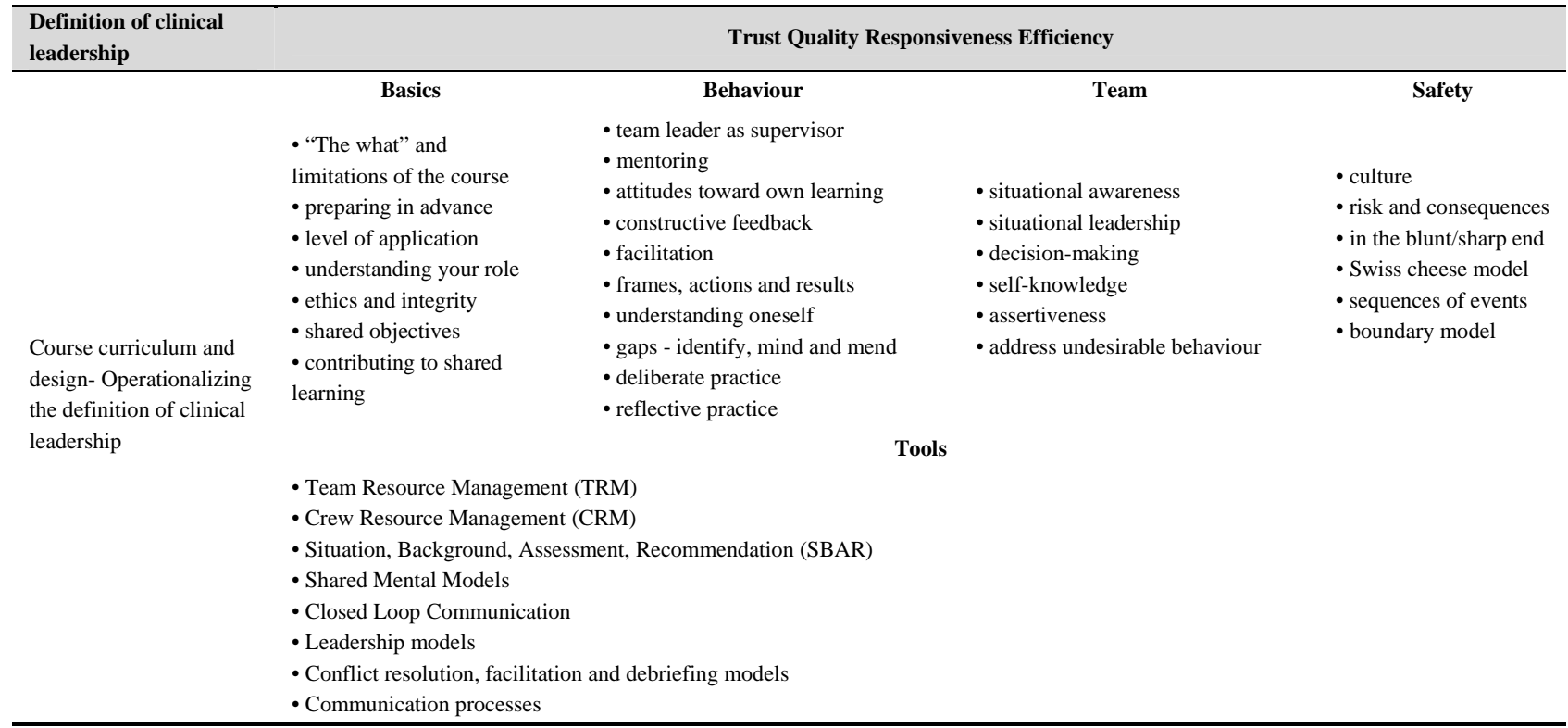

\subsubsection{Linking values to context}

The CLT course comprises four steps (see Table 2). First the participants are introduced to the course background and formative concepts and definition. Next they are introduced to the theoretical and practical dimensions of the specific non-technical skills and human factors tools emerging from the systems engineering and organizational safety evidence base. The participants are then exposed to realistic scenarios, debriefing and group work sessions in which these tools are used to facilitate reflections and internalization of the concepts. These sessions have been specifically designed to include situations and challenges relevant to the participants' daily work. Quality deviation reports and case studies from the participants' wards are analysed and integrated into the simulation and group work exercises in preparation of each course. Examples of simulation scenarios developed from quality deviation reports are included in Table 3. Every course will therefore be different in that it will reflect different challenges and settings depending on the wards involved. Finally, the participants continue this reflection process through facilitated group discussions over a period of up to 3 months. This final step is designed to further link the content of the course to the daily challenges and experiences of the participants. Table 2 also provides a description of the resources needed to implement each step.

To secure sustainability over time, the design specifies the inclusion of past participants of the course to be included in the course faculty through a "Train the trainer's" concept. Although key formative input is continuously needed by faculty staff from SAFER, UiS and SUH to secure a rigorous methodological approach and academic input, past participants contribute greatly to ensuring legitimacy of the content to the wards and department setting, as well as to the resource pool needed over time as new courses are conducted. All use of personnel is approved by hospital management.

\section{RESUlts}

By the end of 2015 a total of 82 participants will have completed the CLT course. The course has been described within the hospital as being timely, given the current Norwegian 
health policy developments. In addition, the hospital has given particular attention to the long-standing challenge of overcrowding and prolonged length of stay in the wards. Ward and department managers are eager to seek new and innovative strategies to address this challenge. The CL in teams' course has been acknowledged to provide an important framework and training to enable clinical wards to tackle this challenge. A new definition of CL has provided a common formative framework useful in clinical settings for priority setting, evaluation and professional development.

Table 2. Structure and steps of the CLT course

\begin{tabular}{|c|c|c|c|c|}
\hline \multirow{2}{*}{ Steps } & Step 1 & \multicolumn{2}{|c|}{ Step 2 and 3} & \multirow{2}{*}{$\begin{array}{r}\text { Step } 4 \\
\text { Implementation }\end{array}$} \\
\hline & Theory & Workshop & Simulation & \\
\hline $\begin{array}{l}\text { Main topics } \\
\text { and objectives }\end{array}$ & $\begin{array}{l}\text { - Introduction } \\
\text { - Acquisition of knowledge } \\
\text { - Foundation theory }\end{array}$ & $\begin{array}{l}\text { - Skill development } \\
\text { - Decision-making } \\
\text { - Introduction to simulation } \\
\text { - Understanding the CLT } \\
\text { framework }\end{array}$ & $\begin{array}{l}\text { - Apply theory in practice, } \\
\text { establish own competence } \\
\text { - Fluency and further development } \\
\text { - From beginner to advanced } \\
\text { competency levels } \\
\text { - Establish teamwork }\end{array}$ & $\begin{array}{l}\text { - Debriefing of actual } \\
\text { experience } \\
\text { - Transfer of knowledge to } \\
\text { clinical practice } \\
\text { - Sustainability and growth }\end{array}$ \\
\hline Methods & $\begin{array}{l}\text { - Self-study } \\
\text { - Course booklet with assignments }\end{array}$ & $\begin{array}{l}\text { - Case studies in groups } \\
\text { (1-day) }\end{array}$ & - Simulation at SAFER (1-day) & $\begin{array}{l}\text { - Group counselling and } \\
\text { debriefing ( } 4 \text { meetings, } 1.5 \text { h) } \\
\text { - One individual coaching } \\
\text { session }\end{array}$ \\
\hline Localization & $\begin{array}{l}\text { - One hour introduction in-hospital. } \\
\text { Self-study allocated to read booklet } \\
\text { and answer questions }\end{array}$ & $\begin{array}{l}\text { - External session (SAFER) } \\
\text { (1-day) }\end{array}$ & $\begin{array}{l}\text { - External session (SAFER) } \\
\text { (1-day) }\end{array}$ & • In-hospital \\
\hline $\begin{array}{l}\text { Resources } \\
\text { needed }\end{array}$ & $\begin{array}{l}\text { - } 1 \text { faculty } \\
\text { - No need for additional instructors }\end{array}$ & $\begin{array}{l}\cdot 2 \text { faculty } \\
\cdot 1 \text { additional facilitator per } \\
5 \text { participants (1-day) }\end{array}$ & $\begin{array}{l}\cdot 2 \text { faculty } \\
\text { - } 1 \text { additional facilitator per } 5 \\
\text { participants (1-day) }\end{array}$ & $\begin{array}{l}\text { - } 1 \text { faculty } \\
\text { - } 1 \text { additional facilitator per } 5 \\
\text { participants ( } 3 \text { meetings,1.5h) }\end{array}$ \\
\hline
\end{tabular}

Table 3. Examples of simulation and group work scenarios included in the CLT course

\begin{tabular}{|c|c|c|}
\hline Scenarios & Objectives & Short description (based on actual cases) \\
\hline $\begin{array}{l}\text { Scenario } 1 . \\
\text { Limited trauma with chest } \\
\text { pain }\end{array}$ & $\begin{array}{l}\text { - identification of prioritized actions } \\
\text { - leadership } \\
\text { - teamwork }\end{array}$ & $\begin{array}{l}\text { A female, } 68 \text { years old, with no known medical history, fell on bike downhill } \\
\text { is transported to the ED in ambulance }\end{array}$ \\
\hline $\begin{array}{l}\text { Scenario } 2 . \\
\text { Lack of resources/ } \\
\text { Overcrowding in the wards }\end{array}$ & $\begin{array}{l}\text { - situational awareness } \\
\text { - apply leadership techniques }\end{array}$ & $\begin{array}{l}\text { A male, } 45 \text { years old, is admitted to the ED afebrile with a lot of coughing and } \\
\text { atrial flutter. He needs cardiac monitoring, but no relevant departments have } \\
\text { bed space }\end{array}$ \\
\hline $\begin{array}{l}\text { Scenario } 3 . \\
\text { Prolonged length of stay in } \\
\text { the ED }\end{array}$ & $\begin{array}{l}\text { - identification of responsible professional for the patient } \\
\text { - ensuring progress } \\
\text { - prioritizing actions and distribution of resources }\end{array}$ & $\begin{array}{l}\text { A } 85 \text { year old demented female, accompanied by her daughter, is admitted to } \\
\text { the ED at five o'clock in the afternoon with suspected femoral neck fracture. } \\
\text { Eight o'clock the next morning she is still in the ED waiting for a clinical } \\
\text { decision to be made }\end{array}$ \\
\hline $\begin{array}{l}\text { Scenario } 4 . \\
\text { Unclarified patient }\end{array}$ & $\begin{array}{l}\text { - collaborate with relevant specialities to make a decision } \\
\text { regarding the patient }\end{array}$ & $\begin{array}{l}\text { A female, aged } 52 \text { is brought to the ED by her husband with suspected chest } \\
\text { pain and syncope but during examination an ankle fracture is detected }\end{array}$ \\
\hline $\begin{array}{l}\text { Scenario } 5 . \\
\text { Bullying at work }\end{array}$ & $\begin{array}{l}\text { - defusing and professional guidance on the shift } \\
\text { - maintaining progress and flow }\end{array}$ & $\begin{array}{l}\text { A doctor realizes a colleague has been bullied by her senior doctor. She is } \\
\text { distracted and distraught reducing her ability to function during the shift }\end{array}$ \\
\hline $\begin{array}{l}\text { Scenario } 6 . \\
\text { Medication error with } \\
\text { consequences }\end{array}$ & $\begin{array}{l}\text { - defusing and professional guidance on busy shift } \\
\text { - handling breaches in procedures with potentially } \\
\text { serious consequences during a shift }\end{array}$ & $\begin{array}{l}\text { A nurse and doctor were involved in a medication error with serious } \\
\text { consequences due to a misunderstanding }\end{array}$ \\
\hline
\end{tabular}

In addition the CLT course has proven to be feasible and sustainable within the scope of existing resources. This is mainly due to the very close relationship between the hospital, SAFER and the University of Stavanger. The course has been developed through existing collaborative structures successfully complying with a no-cost leadership ultimatum. In addition the course has been developed based on available evidence and practice. The seven evidence-based factors outlined by Salas et al. were agreed to be pre-requisites for the success of the course: (1) align team training objectives and safety aims with organizational goals, (2) provide organizational support for the team training initiative,
(3) get frontline care leaders on board, (4) prepare the environment and trainees for team training, (5) determine required resources and time commitment and ensure their availability, (6) facilitate application of trained teamwork skills on the job, and (7) measure the effectiveness of the team training program. ${ }^{[31]}$

The preliminary evaluation of the course has highlighted the importance of adequate buy-in at top and middle management levels within the hospital. Another important element is the sustainability design of the course involving previous participants in the implementation of subsequent courses. 
The course design has also proven to be flexible and relevant to each participant. Each course has successfully been tailored to fit the challenges and ward realities of the participants. This has been secured through the described process involving key clinical staff and ward managers in the preparatory process of each course. In addition evaluations from participants, course faculty and ward managers have continuously been fed into the planning phases of each course.

The preliminary feedback from the participants has also been very positive. Structured evaluations of each course indicate that the participants have found the courses to be timely and relevant, providing a forum for discussion and reflection on the daily decision-making challenges faced in their clinical setting.

The course has been set up with a separate action research protocol. This protocol will assess the impact of the course, specifically focusing on the four values and implementation and sustainability aspects. This final evaluation will be conducted early 2016, to be published in separate accounts.

\section{DisCUSSION AND CONCLUSIONS}

This article presents a reformulation of the CL concept rooted in the need for clinical personnel to take responsibility for clinical decision-making with a patient-centred perspective based on a specific set of health systems values in a clinical setting. It also describes the development of a CLT course for clinical personnel relevant to their own specific context. Finally, it briefly evaluates the timeliness, feasibility, flexibility and relevance of the course so far. The background of the course was based on current Norwegian health policy developments and the need to institutionalize a process to replace the vacant traditional senior-to-junior nurse and doctor apprenticeship relationship in which values previously were transferred.

The definition of CL is reformulated to take into account the skills needed to take responsibility for clinical decisions with a particular focus on reflecting on how these decisions will impact on four key values considered to be important outcomes of these decisions. These values have been derived from global health systems values descriptions and adapted to a clinical setting. They are trust, quality, responsiveness and efficiency. In the review of Mannix et al. it is demonstrated that definitions of CL have a clinical focus, a follower/team focus or a personal qualities focus. ${ }^{[15]}$ Most CL characteristics include attributes reflecting technical and practical skills necessary for competent clinical practice and leading a team. Howieson and Thiagarajah ${ }^{[63]}$ found that most literature is centered on recommended leadership behaviour, traits and competencies. The behaviour of clinical leaders is influenced by their values and beliefs and affects patient care and relationships with others. ${ }^{[64]}$ Values affect how clinical leaders operate and have important effects on their leadership abilities and how they respond to challenges. Therefore, for any clinical leaders and teams to work effectively, it is crucial to develop common basic values and beliefs. ${ }^{[64]}$ Successful accomplishment and positive evaluation of the first 7 courses has shown that the value-based definition is robust and well understood. Linking values to tools and context to translate these values into every day CL practice has also proven to be useful. Basing the course development on best-evidence and practice, and curriculum on the systems engineering, non-technical skills, human factors and organizational safety scientific platform provides an evidence based framework enabling a validated and comparable improvement process, also with other national and international hospital and scientific partners.

A limitation is that reformulation of the CL concept to the four core values is not based on contextualized empirical evidence but on formative and theoretical research concepts and scientific accounts from other contexts. Further studies have to be performed to address empirical evidence for the reformulated CL concept and the four values, assessment of the learning, transfer to clinical practice and long term effects on patient outcomes in a clinical setting.

The strength of the development process of the CLT course is its close link to hospital, Norwegian, European and global health policy objectives and debates. ${ }^{[65-67]}$ Healthcare personnel and patients also emphasize values as important in providing patient-centered care and treatment. ${ }^{[68-70]}$ Another strength of the CLT course is that the curriculum is rooted in the actual clinical setting of the participants using local, empirically based inputs for preparing, developing and sustaining CL in team skills. ${ }^{[37]}$ Output of the CLT course will hopefully also in the long run demonstrate improvement in patient-centered care and workforce satisfaction through improved reflection and implementation of the four core values bedside.

\section{ACKNOWLEDGEMENTS}

This research was funded by Stavanger Acute care Research group (SAR) also with support from the Western Norway Regional Health Authority (seed money). The opinions in the present paper are those of the authors and do not necessarily reflect the sponsor's official position. 


\section{REFERENCES}

[1] Loughlin M. Ethics, Managament and mythology. Rational decision making for health service professionals. Oxon, United Kingdom: Radcliffe Medical Press; 2002.

[2] Macintyre A. After virtue: A study in moral theroy. Third ed, ed. U.o.N. Dame. Notre Dame, Indiana, USA: University of Notre Dame Press; 2007.

[3] Wyller VB, Gisvold SE, Hagen E, et al. Reclaim the profession! Tidsskr Nor Laegeforen. 2013; 133(6): 655-9. PMid: 23552162. http://dx.doi.org/10.4045/tidsskr.13.0238

[4] Foss BN. Dagfinn. Eriksson, Katie, Toward a new leadership model: to serve in responsibility and love. International Journal for Human Caring. 2014; 18(3): 9.

[5] Doan Q, Sabhaney V, Kissoon N, et al. A systematic review: The role and impact of the physician assistant in the emergency department. Emergency Medicine Australasia. 2011; 23(1): 7-15. PMid: 21284809. http://dx.doi.org/10.1111/j.1742-6723.2010 $.01368 \cdot \mathrm{x}$

[6] Guedes dos Santos JL, da Silva Lima MAD, Pestana AL, et al. Challenges for the management of emergency care from the perspective of nurses. Acta Paulista de Enfermagem. 2013; 26(2): 136-143.

[7] Bjørnsen LP, Uleberg O. Mottaksmedisin - akuttmedisinens sorte får [Emegency Medicine -The black sheep of Acute Medicine]. Tidsskrift For Den Norske Lægeforening. 2012; 8(132): 931. PMid: 22562320. http://dx.doi.org/10.4045/tidsskr.12.0208

[8] Sanders K, Pattison S, Hurwitz B. Tracking shame and humiliation in Accident and Emergency. Nursing Philosophy. 2011; 12: 83-93. PMid: 21371246. http://dx.doi.org/10.1111/j.1466-769X. $2010.00480 . x$

[9] NBHS. "While we are waiting....." - do patients receive adequate treatment in accident and emergency units? Norwegian Board of Health Supervision. 2008.

[10] NBHS and N.B.o.H.S.i. Rogaland. Follow-up evaluation in the Emergency Department, Stavanger University Hospital. 2013.

[11] Health, D.o. Fremtidens legespesialister. En gjennomgang av legers spesialitetsstruktur og -innhold. (Future medical specialties - structure and content), G.o. Norway, Editor. Government of Norway. 2014. PMid: 25197899.

[12] Health, D.o. Kommnenes plikt til øyeblikkelig hjelp døgnopphold. Veiledningsmateriell. (The obligation of municipal councils to provide emergency services. Implementation guides). Government of Norway: Oslo, Norway; 2014. 37.

[13] Welfare, D.o.H.a.S. Akuttmedisinforskriften (Emergency Medicine regulation), G.o. Norway, Editor. Government of Norway: Oslo, Norway; 2015.

[14] Rocchiccioli J, Tilbury MS. Clinical leadership in nursing. Saunders (Philadelphia). 1998. PMid: 9745420.

[15] Mannix J, Wilkes L, Daly J. Attributes of clinical leadership in contemporary nursing: An integrative review. Contemporary Nurse: A Journal for the Australian Nursing Profession. 2013; 45(1): 10-21. PMid: 24099222. http://dx.doi .org/10.5172/conu. 2013.4 5.1 .10

[16] NHS. Leadership Development Framework for Discussion. National Health Service, Scotland. 2004.

[17] Cook A, Holt L. Clinical leadership and supervision, in Accident \& emergency : theory into practice. Edinburgh: Baillière Tindall Elsevier; 2008. 497-503.

[18] McNamara MS, Fealy GM, Casey M, et al. Boundary matters: clinical leadership and the distinctive disciplinary contribution of nursing to multidisciplinary care. Journal of Clinical Nursing. 2011; 20(23/24): 3502-3512. PMid: 21631616. http://dx .doi.org/1 $0.1111 / j .1365-2702.2011 .03719 . x$

Published by Sciedu Press
[19] Millward LJ, Bryan K. Clinical leadership in health care: a position statement. International Journal of Health Care Quality Assurance. 2005; 18(2/3): R13-R25. http://dx.doi.org/10.1108/13660 750510594855

[20] Dickinson H, Ham C. Engaging Doctors in Leadership: Review of the Literature. Health Services Management Centre, University of Birmingham. 2008.

[21] Øvretveit J, Andreen Sachs M. Good leadership adds value to quality improvement. Swedish Medical Journal. 2010; 107(11): 764-766.

[22] Goldman EF, Plack MM, Roche CN, et al. Learning clinical versus leadership competencies in the emergency department: strategies, challenges, and supports of emergency medicine residents. Journal Of Graduate Medical Education. 2011; 3(3): 320-325. PMid: 22942956. http://dx.doi.org/10.4300/JGME-D-10-00193.1

[23] Kuntz L, Mennicken R, Scholtes S. Stress on the Ward: Evidence of Safety Tipping Points in Hospitals. Management Science. 2015; 61(4): 754-771. http://dx.doi.org/10.1287/mnsc . 2014.191 7

[24] Fernandez R, Vozenilek JA, Hegarty CB, et al. Developing Expert Medical Teams: Toward an Evidence-based Approach. Academic Emergency Medicine. 2008; 15(11): 1025-1036. PMid: 18785937. http://dx.doi.org/10.1111/j.1553-2712.2008.00232.x

[25] Beniuk K, Boyle AA, Clarkson PJ. Emergency department crowding: prioritising quantified crowding measures using a Delphi study. Emergency Medicine Journal. 2012; 29(11): 868-871. PMid: 22199142 http://dx.doi.org/10.1136/emermed-2011-200646

[26] Tvedt C, Sjetne IS, Helgeland J, et al. A cross-sectional study to identify organisational processes associated with nurse-reported quality and patient safety. BMJ Open. 2012 Dec 20; 2(6). PMid: 23263021 http://dx.doi:10.1136/bmjopen-2012-001967

[27] Reader TW, Flin R, Cuthbertson BH. Team leadership in the intensive care unit: the perspective of specialists. Critical Care Medicine. 2011; 39(7): 1683-1691. PMid: 21460708. http://dx.doi.org/10.10 97/CCM. Ob013e318218a4c7

[28] Reader TW, Flin R, Mearns K, et al. Developing a team performance framework for the intensive care unit. Critical Care Medicine. 2009; 37(5): 1787-1793. PMid: 19325474. http://dx.doi.org/10.10 97/CCM. Ob013e31819f0451

[29] Manser T. Teamwork and patient safety in dynamic domains of healthcare: a review of the literature. Acta Anaesthesiologica Scandinavica. 2009; 53(2): 143-151. PMid: 19032571. http://dx.doi.org/10. $1111 / j .1399-6576.2008 .01717 . x$

[30] Rabø1 LI, Andersen ML, Østergaard D, et al. Descriptions of verbal communication errors between staff. An analysis of 84 root cause analysis-reports from Danish hospitals. BMJ Quality \& Safety. 2011; 20(3): 268-274. PMid: 21209139. http://dx.doi.org/10.1136 /bmjqs. 2010.040238

[31] Cleary M, Freeman A, Sharrock L. The development, implementation, and evaluation of a clinical leadership program for mental health nurses. Issues in Mental Health Nursing. 2005; 26(8): 827-842. PMid: 16203638. http://dx.doi.org/10.1080/01612840500 184277

[32] Cole E, Crichton N. The culture of a trauma team in relation to human factors. Journal of Clinical Nursing. 2006; 15(10): 1257-1266. PMid: 16968430. http://dx.doi.org/10.1111/j.1365-2702. $2006.01566 . \mathrm{x}$

[33] Burström L, Nordberg M, Ornung G, et al. Physician-led team triage based on lean principles may be superior for efficiency and quality? A comparison of three emergency departments with different triage models. Scandinavian Journal Of Trauma, Resuscitation And Emergency Medicine. 2012; 20: 57-57. PMid: 22905993. http://dx.doi.org/10.1186/1757-7241-20-57 
[34] Capella J, Smith S, Philp A, et al. Teamwork training improves the clinical care of trauma patients. Journal Of Surgical Education. 2010; 67(6): 439-443. PMid: 21156305. http://dx.doi.org/10.1016 $/ j \cdot j$ surg. 2010.06.006

[35] Baker DP, Day R, Salas E. Teamwork as an essential component of high-reliability organizations. Health Serv Res. 2006; 41(4): 15761598. PMid: 16898980. http://dx.doi.org/10.1111/j.147 5-6773.2006.00566.x

[36] Kohn L, Corrigan J, Donaldson M. To err is human: building a safer health system. Washington, USA: National Academy Press; 2000 287.

[37] Salas E, Almeida SA, Salisbury M, et al. What Are the Critical Success Factors for Team Training in Health Care? The Joint Commission Journal on Quality and Patient Safety. 2009; 35(8): 398-405. PMid: 19719075.

[38] Kohn LT, Corrigan J, Donaldson MS. To err is human: building a safer health system. Washington, DC: National Academy Press; 2000.

[39] Warren OJ, Carnall R. Medical leadership: why it's important, what is required, and how we develop it. Postgraduate Medical Journal. 2011; 87(1023): 27-32. PMid: 20935344. http://dx.doi.org/1 $0.1136 /$ pgmj . 2009.093807

[40] Ham C. Improving the performance of health services: the role of clinical leadership. Lancet. 2003; 361(9373): 1978-1980. http: //dx.doi.org/10.1016/S0140-6736(03) 13593-3

[41] Danis M, Clancy C, Churchill L. Ethical dimensions of health policy. Oxford, England: Oxford University Press. 2002.

[42] Murray CJ, Evans DB. Health systems performance assessment: debates, methods and empiricism. Geneva: World Health Organization; 2003. 900 .

[43] Giddens A. The consequences of modernity. Cambridge: Polity; 1990.

[44] McEvily B, Weber RA, Bicchieri C, et al. Can groups be trusted? An experimental study of trust in collective entities. Handbook of trust research, R. Bachmann and A. Zaheer, Editors. Edward Elgar: Cheltenham; 2006. 52-67.

[45] Berg RL, Cassells JS. The second fifty years: Promoting health and preventing disability. National Academy Press; 1990.

[46] Donabedian A. The quality of care. How can it be assessed? Journal Of The American Medical Association. 1988; 260(12): 1743-1748. http://dx.doi.org/10.1001/jama.1988.03410120089033

[47] Wilde Larsson B, Larsson G. Development of a short form of the Quality from the Patient's Perspective (QPP) questionnaire. Journal Of Clinical Nursing. 2002; 11(5): 681-687. http://dx.doi.org /10.1046/j.1365-2702.2002.00640.x

[48] Hollnagel E. Safety I and Safety - II. The past and future of safety management . Farnham: Ashgate; 2014. 200.

[49] Deming W. Quality, Productivity and Competitive Position. Massachusetts Institute of Technology, Cambridge. 1982.

[50] WHO, D.S. A Framework for Measuring Responsiveness. Paper Series no. 32 (Geneva:WHO, 2000EIP/GPE/EBD World Health Organization. 2000

[51] Merson MH, Black RE, Mills AJ. International Public Health. Diseases, Programs, Systems, and Policies. Gaithersburg, Maryland, USA: Aspen Publishers; 2001. 757.

[52] Espejord M, Lægreid HJ. Effektivitetsanalyse av somatiske sengeposter ved Universitetssykehuset Nord-Norge HF: en prestasjonsmåling ved bruk av DEA og SFA (Analysis of effectivity on somatic units in the University hospital of North of Norway). Troms $\varnothing$ : Universitetet i Tromsø; 2012.
[53] Ozcan Y. Health Care Benchmarking and Performance Evaluation: An Assessment Using Data Envelopment Healthcare Benchmarking and Performance Evaluation: Analysis (DEA). 2008. http: //dx.doi.org/10.1007/978-0-387-75448-2

[54] AHRQ. Health Care Efficiency Measures: Identification, Categorization, and Evaluation (Chapter 2. Methods). The Agency for Healthcare Research and Quality. 2008.

[55] Øvretveit J. Evaluating health interventions: an introduction to evaluation of health treatments, services policies and organizational interventions. Open University Press. 2005.

[56] Daniels N, Sabin JE. Accountability for reasonableness: an update. BMJ (Clinical Research Ed.). 2008; 337: 1850. PMid: 18845595. http://dx.doi.org/10.1136/bmj . a1850

[57] Salamon SD, Robinson SL. Trust that binds: The impact of collective felt trust on Organizational Performance. Journal of Applied Psycology. 2008; 93(3): 593-601. PMid: 18457488. http: //dx.doi.org/10.1037/0021-9010.93.3.593

[58] Sztompka P. Trust: A Sociological Theory. Cambridge University Press. 1999. PMid: 10581672.

[59] Hollnagel E. The ETTO Principle: Efficiency - Thoroughness TradeOff. Why things that go right sometimes go wrong. Farnham: Ashgate; 2009. 162 .

[60] Cook R, Rasmussen J. "Going solid": a model of system dynamics and consequences for patient safety. Qual Saf Health Care. 2005; 14(2): 130-4. PMid: 15805459. http://dx.doi.org/10.1136/q shc. 2003.009530

[61] Dekker SW, Hancock PA, Wilkin P. Ergonomics and sustainability: towards an embrace of complexity and emergence. Ergonomics. 2013; 56(3): 357-64. PMid: 23006035. http://dx.doi.org/10. 1080/00140139.2012.718799

[62] Xie A, Carayon P. A systematic review of human factors and ergonomics (HFE)-based healthcare system redesign for quality of care and patient safety. Ergonomics. 2015; 58(1): 33-49. PMid: 25323570. http://dx.doi.org/10.1080/00140139.2014.959070

[63] Howieson BT. Thiagarajah, What is clinical leadership? A journalbased meta-review. International Journal of Clinical Leadership. 2011; 17(1): 7-18.

[64] Clark L. Clinical leadership: values, beliefs and vision. Nursing Management - UK. 2008; 15(7): 30-35. PMid: 19024882. http: //dx.doi.org/10.7748/nm2008.11.15.7.30.c6807

[65] Smith PC. Part I. Principles of performance measurement, in Performance Measurement for Health System Improvement. Experiences, Challenges and Prospects. Cambridge University Press: Cambridge; 2009. 3-24.

[66] Hanoa R. Triage and follow-up in emergency departments. Tidsskrift For Den Norske Lægeforening: Tidsskrift For Praktisk Medicin, Ny Række. 2013; 133(3): 262-262. PMid: 23381149. http://dx.doi .org/10.4045/tidsskr.13.0019

[67] Supervision. N.B.o.H. 2014. Available from: http://www.helset ilsynet.no/Norwegian-Board-of-Health-Supervision/

[68] Flink M, Hesselink G, Pijnenborg L, et al. The key actor: a qualitative study of patient participation in the handover process in Europe. BMJ Quality \& Safety. 2012; 21: 89-96. PMid: 23112290. http://dx.doi.org/10.1136/bmjqs-2012-001171

[69] Gaudine A, Thorne L. Nurses' ethical conflict with hospitals: A longitudinal study of outcomes. Nursing Ethics. 2012; 19(6): 727-737. PMid: 22619238. http://dx.doi.org/10.1177/09697330114 21626

[70] Borgstrom E, Cohn S, Barclay S. Medical Professionalism: Conflicting Values for Tomorrow's Doctors. Journal of General Internal Medicine. 2010; 25(12): 1330-1336. PMid: 20740324. http: //dx.doi.org/10.1007/s11606-010-1485-8 